\title{
Epoetin-alfa induced pruritic maculopapular eruption: Case report and literature review
}

\author{
Rawi Rueangsri, Wannada Laisuan
}

\begin{abstract}
Background: Erythropoiesis-stimulating agents (ESA) are commonly used in clinical practice to improve anaemia. Despite a number of patients successfully treated without adverse events, the complications have been previously reported.

Objective: To report and review the characteristics and management of ESA hypersensitivities.

Method: Case reports and related articles associated with ESA use, published between January 1999 and December 2018 , were retrieved through Electronic databases $\left(\mathrm{MEDLINE}^{\oplus}\right.$ and $\mathrm{PubMed}^{\circledR}$ ).

Result: Forty-seven ESA patients with various immediate and delayed hypersensitivity reactions caused by epoetin and pharmaceutical excipients were identified from nineteen studies and one case report in this paper. Fatal hypersensitivity to ESA and ESA-allergic cross-reactivities have been documented. Desensitization or change of EPO molecular structure has been reported as successful methods of re-introducing the drug.
\end{abstract}

Conclusion: ESA hypersensitivity in the various allergic reactions and cross-reactivity have been documented. Desensitization and Epoetin structural changes could be successful methods to re-introduce the drug.

Key words: Erythropoietin; Drug hypersensitivity; Anaphylaxis; Drug eruptions, Epoetin hypersensitivity

\section{From:}

Division of Allergy Immunology and Rheumatology,

Department of Medicine, Faculty of Medicine, Ramathibodi Hospital,

Mahidol University, Bangkok, Thailand.

\section{Introduction}

The erythropoiesis-stimulating agent (ESA) have been widely prescribed in cancer-associated anemia and chronic kidney disease. Adverse reactions to erythropoietin rarely occur. However, prescribers should be aware of the following possible side effects; pure red cell aplasia (PRCA), susceptibility of cardiovascular events and hypersensitivity reactions. This study focuses on case reports of ESA allergic patients, published reviews, and research articles.

\section{Methods}

Ethical approval has been granted by the committee on human rights related to research involving human subjects, Mahidol university. The approval number is MURA2018/191.

Case reports and related researches published between January 1999 and December 2018 in allergic patients associated with ESA use were retrieved and compiled through Electronic databases (MEDLINE ${ }^{\circledast}$ and PubMed ${ }^{\circledast}$ ).
Corresponding author:

Wannada Laisuan

E-mail: wannada.lai@mahidol.ac.th

\section{Case report}

A 50-year-old-male, draftsman with hypertension, dyslipidemia and chronic kidney disease caused by contrast-induced nephropathy status on hemodialysis twice a week was prescribed subcutaneous injection of epoetin- $\alpha$ for the treatment of anemia due to chronic kidney disease. Currently taking medications are furosemide, simvastatin, metoprolol, calcium carbonate, ferrous sulphate, sodium bicarbonate and folic acid. He denied the previous history of atopic disease. About 3 weeks after the injection of epoetin- $\alpha$, he developed pruritic rash. Physical examination revealed generalized pruritic maculopapular rashes on his body and limbs without mucosal involvement. Laboratory investigations showed white blood cell count $10.48 \times 10^{3} /$ cumm (4.00-10.00), Neutrophil 69\% (40-74), Lymphocyte 26\% (19-48), Eosinophil 5\% (0-7), Hemoglobin 7.4 g/dL (13.00-18.00), Hematocrit 23\% (40-54) and Platelets $200 \times 10^{3} /$ cumm (140-450). Liver function test was normal as aspartate aminotransferase $8 \mathrm{U} / \mathrm{L}$ (5-34) and alanine aminotransferase $15 \mathrm{U} / \mathrm{L}(0-55)$. 
Table 1. Results of skin tests with different commercial available brands of epoetin alfa.

\begin{tabular}{|c|c|c|c|c|}
\hline & \multirow{2}{*}{ Prick } & \multicolumn{2}{|c|}{ Intradermal test $(0.02 \mathrm{ml})$} & \multirow{2}{*}{$\begin{array}{c}\text { Patch test }(96 \mathrm{hr} \text { ) } \\
\text { Undiluted }\end{array}$} \\
\hline & & $48 \mathrm{hr}$. & $96 \mathrm{hr}$. & \\
\hline Positive Control (Histamine) & Positive & NT & NT & NT \\
\hline Negative Control (Normal saline) & Negative & NT & NT & Negative \\
\hline EPO- $\alpha\left(\right.$ EPIAO $\left.^{\circ}\right)$ & Negative & Negative & Negative & Negative \\
\hline EPO- $\alpha\left(\right.$ EPOGEN $\left.^{\circledR}\right)$ & Negative & Negative & Negative & Negative \\
\hline EPO- $\beta\left(\right.$ RECOMMON $\left.{ }^{*}\right)$ & NT & NT & NT & Negative \\
\hline $5 \%$ Polysorbate- 80 & NT & NT & NT & Negative \\
\hline Sodium citrate & NT & NT & NT & Negative \\
\hline
\end{tabular}

NT: not tested

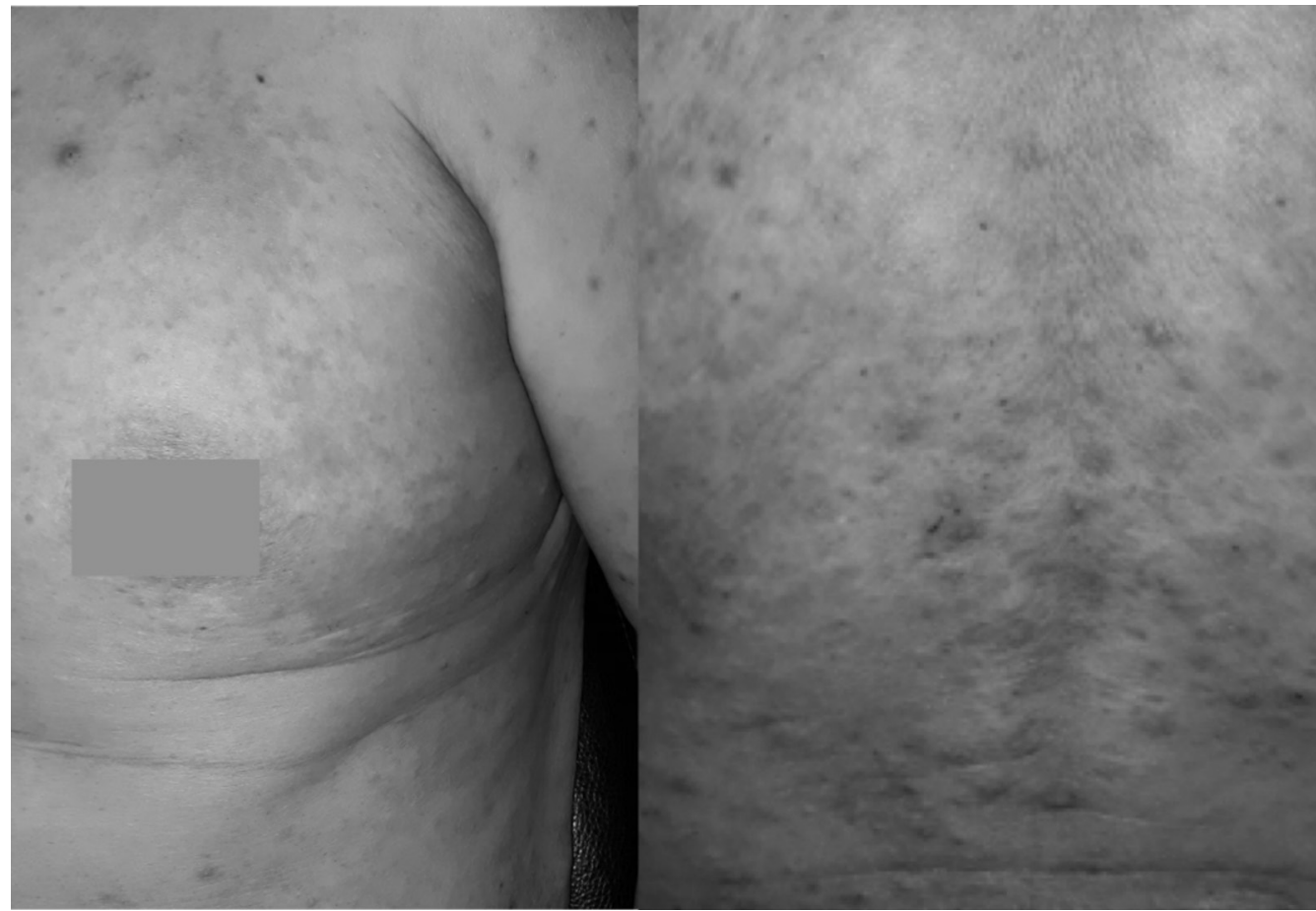

Figure 1. The diffuse erythematous pruritic maculopapular eruption after 10-day of epoetin-alpha provocation test.

Drug discontinuation was suggested due to the suspicion of delayed allergic reaction to epoetin- $\alpha$ and then referred to allergist for further management. Intradermal skin test and patch test were applied with the negative reactions (Table 1). Epoetin-a hypersensitivity was diagnosed by drug provocation test with epoetin- $a$ resulted in the re-occurrence of pruritic rashes after 10 days of the subcutaneous injection. After the skin has recovered, patch testing with different epoetin structure, preservatives and excipients showed no reaction (Table 1). Epoetin- $\beta$ (Recommon ${ }^{\circledast} 2,000 \mathrm{IU} / 0.3 \mathrm{~mL}$ ) was reintroduced twice a week by slow graded challenge started from $0.05 \mathrm{~mL}$ then double up dose until reach therapeutic level (12,000 IU/ week) which had been achieved without adverse effects. The patient has continued epoetin- $\beta$ treatment for 1-year follow-up without any reactions.

\section{Discussion}

A total of 19 publications during the two decades met the inclusion criteria (Table 2) including the case report in this study. Forty-seven ESA hypersensitivity patients with various immediate and delayed hypersensitivity allergic reactions caused by epoetin and pharmaceutical excipients have been reported.

The pharmaceutical excipients, gelatin and polysorbate, play a major role for the anaphylaxis in three cases of ESA associated hypersensitivity. ${ }^{1-3}$ Reactive skin testing to polysorbate was shown in two cases and anti-bovine gelatin IgE was found in the case of gelatin hypersensitivity. Polysorbate hypersensitivity could also present with delayed reaction as a generalized dermatitis with superficial desquamation. ${ }^{4}$ 
Table 2. Publications reporting ESA-allergic reactions.

\begin{tabular}{|c|c|c|c|c|}
\hline Author/year & ESA & Allergic reaction & $\begin{array}{l}\text { Definite } \\
\text { causation }\end{array}$ & Remarks \\
\hline $\begin{array}{l}\text { Sakaguchi, } \\
1999^{1}\end{array}$ & $\begin{array}{l}\text { Epoetin alfa } \\
\text { Epoetin beta }\end{array}$ & Anaphylaxis & Gelatin & $\begin{array}{l}\text { - Anti-bovine gelatin IgE detectable. } \\
\text { - Anti-EPO IgE undetectable. }\end{array}$ \\
\hline Limaye, $2002^{2}$ & Epoetin alfa & Anaphylaxis & Polysorbate & $\begin{array}{l}\text { - Reactive skin test with polysorbate-containing agents } \\
\text { but non-reactive with polysorbate-free darbepoetin } \\
\text { alfa. }\end{array}$ \\
\hline Steele, $2005^{3}$ & Darbepoetin alfa & $\begin{array}{l}\text { Urticaria with orofacial } \\
\text { angioedema }\end{array}$ & Polysorbate & $\begin{array}{l}\text { - Reactive skin testing with polysorbate and } \\
\text { polysorbate-containing agents. } \\
\text { - Safely used polysorbate-free darbepoetin alfa. }\end{array}$ \\
\hline Cholongitas, $2010^{4}$ & Darbepoetin alfa & $\begin{array}{l}\text { Generalized dermatitis with } \\
\text { superficial desquamation }\end{array}$ & & $\begin{array}{l}\text { - Safely used polysorbate } 80 \text {-free formulation } \\
\text { erythropoietin. }\end{array}$ \\
\hline Garcia, $1993^{5}$ & $\begin{array}{l}\text { Recombinant human } \\
\text { erythropoietin } \\
\text { (rHuEPO) }\end{array}$ & Anaphylactic shock & & $\begin{array}{l}\text { - Skin test with commercial rHuEPO negative. } \\
\text { - Anti-IgE to rHuEPO detected by RAST. }\end{array}$ \\
\hline Weber, $2002^{6}$ & $\begin{array}{l}\text { Epoetin alfa } \\
\text { Epoetin beta } \\
\text { Darbepoetin alfa }\end{array}$ & $\begin{array}{l}\text { Injection site wheals, } \\
\text { anaphylaxis }\end{array}$ & $\begin{array}{l}\text { Epoetin alfa } \\
\text { Epoetin beta } \\
\text { Darbepoetin } \\
\text { alfa }\end{array}$ & $\begin{array}{l}\text { - Anti-EPO antibodies to epoetin alfa, epoetin beta and } \\
\text { darbepoetin alfa detected. }\end{array}$ \\
\hline
\end{tabular}

Oh, $2014^{7}$

Pegylated epoetin beta

Anaphylactic shock

Bennett, 2014

Peginesatide

Anaphylactic shock/fatal

anaphylaxis

$\begin{array}{lll}\text { Aziz, 20159 } & \text { Epoetin alfa } & \text { Anaphylactic shock } \\ \text { Dávila Fajardo, 2010 } & \begin{array}{l}\text { Epoetin beta } \\ \text { Darbepoetin alfa }\end{array} & \begin{array}{l}\text { Generalized pruritic } \\ \text { micropapular lesions }\end{array} \\ \text { Tahan, 2013 } & \begin{array}{l}\text { Epoetin alfa } \\ \text { Darbepoetin alfa }\end{array} & \begin{array}{l}\text { Pruritic erythematous } \\ \text { maculopapular eruption }\end{array}\end{array}$

Rosa, $2018^{12}$

Epoetin alfa

Darbepoetin alfa

maculopapular rash alfa
Diffuse pruritic

- Strongly reactive skin test with darbepoetin alfa.

- Graded administration with epoetin alfa successful.

- At 19 centers, 5 patients had fatal anaphylaxis, 6 patients had grade 4 anaphylaxis with hypotension,

17 patients had grade 3 anaphylaxis with hypotension.

- Definite causations not identified.

- Resulted in removal of peginesatide from the market.

- Skin test with preservative-free epoetin alfa and darbepoetin alfa positive.

- Desensitization in intensive unit over 3 hours with epoetin alfa successful.

- Safely used pegylated epoetin beta.

- More intense skin reaction (erythematous and desquamation) after darbepoetin alfa administration.

- Skin test with darbepoetin alfa negative.

- 2-day desensitization with darbepoetin alfa successful.

- Anti-epoetin alfa and anti-darbepoetin alfa antibodies not detected with biosensor immunoassay.

- 2-day desensitization with epoetin alfa failed and pruritic maculopapular rash developed.

- Modified outpatient 17-day slow desensitization protocol with low dose prednisolone contributed to tolerance induction.

- It may be assumed that epoetin can induce growth of histiocytes within the skin.

lichenoid granulomatous features

- Persistent and recurrent skin reactions developed

Persistent and recurrent generalized erythema and orofacial angioedema

Darbepoetin for 2 months, despite the use of polysorbate-free

Erythema multiforme/fatal DRESS syndrome darbepoetin alfa and following discontinuation.

- DRESS diagnosed after single dose of epoetin alfa resulting in fatal reaction.

alfa

Skin test with epoetin alfa and darbepoetin alfa negative.

- 2-day desensitization with epoetin alfa successful.

- Skin test and patch test with epoetin alfa and darbepoetin alfa negative.

- 2-day desensitization with epoetin alfa successful. 
Table 2. (Continued)

\begin{tabular}{llll} 
Author/year & ESA & Allergic reaction & $\begin{array}{c}\text { Definite } \\
\text { causation }\end{array}$ \\
\hline Cuxart, $2000^{18}$ & Undefined & Exfoliative dermatitis & \\
Suh, $2018^{19}$ & Undefined & AGEP & Patient was HLA-B44, HLA-B51 positive on genetic \\
analysis.
\end{tabular}

AGEP: acute generalized exanthematous pustulosis, CERA: continuous erythropoietin receptor activator, CKD: chronic kidney disease, CLL: chronic lymphocytic leukemia, DRESS: drug rash with eosinophilia and systemic symptoms, EPO: erythropoietin or epoetin, ESRD: end-stage renal disease, HLA: human leukocyte antigen

In cases of ESA structure hypersensitivity, allergic reactions have been classified as immediate and delayed type hypersensitivity. Four studies reported the immediate reaction as anaphylaxis from ESA. ${ }^{5-9}$ Garcia et al. ${ }^{5}$ and Weber et al. ${ }^{6}$ identified Anti-IgE to recombinant human erythropoietin (rHuEPO) and Anti-EPO antibodies to epoetin- $\alpha$ and $\beta$, respectively. Reactive skin testing was applied for the diagnosis in another two publications. ${ }^{7,9}$ In delayed type hypersensitivity to ESA, the various types of skin manifestations and severity have been documented ranging from pruritic maculopapular rash to exfoliative dermatitis, drug reaction with eosinophilia and systemic symptoms (DRESS) and acute generalized exanthematous pustulosis (AGEP). ${ }^{10-19}$ (Table 2)

A case of ESA allergic patient who presented with generalized pruritic maculopapular rash has been reported in this study. The intradermal skin test and patch test with commercial drug and excipients had been performed with negative results. However, the drug provocation test with Epoetin- $\alpha$ $\left(\mathrm{EPIAO}^{\circledR}\right)$ resulted in generalized pruritic maculopapular rash and he was diagnosed with Epoetin- $\alpha$ hypersensitivity. Because of the negative result of Epoetin- $\beta$ reactivity testing, slow graded challenge was performed without any reactions. This case has allergic to alpha molecular structure of Epoetin-a but not the beta. Three previous publications have also reported epoetin allergic patients who presented with pruritic erythematous maculopapular eruption. ${ }^{10-12}$

The ESA-allergic cross reactivities between molecular structures $\alpha$ and $\beta$ have been documented. ${ }^{6,7}$ Oh et al. reported a patient who had been diagnosed with pegylated epoetin- $\beta$ anaphylaxis, with positive skin testing to epoetin- $\alpha$, epoetin- $\beta$ and darbepoetin-a. However, they reported successful re-introduction by changing the molecular structure of the drug ( $\alpha$ and $\beta$ ). ${ }^{7,10}$

The fatal reaction due to ESA hypersensitivity have been reported in two publications as follows; erythema multiforme and fatal DRESS syndrome 12 hours after epoetin- $\alpha$ subcutaneous administration resulted in the interstitial pneumonitis of systemic reaction indicating DRESS syndrome, ${ }^{15}$ and a multicenter study identified 5 patients who died of severe anaphylaxis after receiving peginesatide in U.S. dialysis care. ${ }^{8}$ The drug was later recalled by the pharmaceutical manufacturer on the $23^{\text {rd }}$ February, 2013 because of concerns about the safety of peginesatide after the report had been published. Manufacturing license have also been withdrawn by the U.S. FDA for new pharmaceutical registration. ${ }^{20}$
Two-day drug desensitization has been reported as a successful method to re-introduce epoetin- $\alpha$ in two cases of AGEP and a case of pruritic erythematous maculopapular eruption. ${ }^{16}$ However, Rosa et al. reported the failure of 2-day desensitization in a case of diffuse pruritic maculopapular rash and $17-$ day slow desensitization protocol with low dose prednisolone had been shown. ${ }^{12}$ Aziz et al. reported a successful 3-hour desensitization in a patient who experienced anaphylaxis from epoetin- $\alpha{ }^{9}$

\section{Conclusion}

ESA hypersensitivity has been reported as both immediate and delayed allergic reactions varying in severity ranging from mild to fatal reactions. Cross-reactivity between the drug molecular structures have been documented. Desensitization and molecular structure changes could lead to a successful method of re-introducing the drug in some cases.

\section{Acknowledgement}

John Kitti Luckit, BSc, MB, BS, MRCPI, MRCPath

Consultant haematologist, BMI Cavell Hospital, London

\section{Conflicts of interest} none

\section{Funding source} none

\section{References}

1. Sakaguchi $M$, Kaneda $H$, Inouye $S$. A case of anaphylaxis to gelatin included in erythropoietin products. J Allergy Clin Immunol. 1999;103 (2 Pt 1):349-50.

2. Limaye S, Steele RH, Quin J, Cleland B. An allergic reaction to erythropoietin secondary to polysorbate hypersensitivity. J Allergy Clin Immunol. 2002;110(3):530.

3. Steele RH, Limaye S, Cleland B, Chow J, Suranyi MG. Hypersensitivity reactions to the polysorbate contained in recombinant erythropoietin and darbepoietin. Nephrology (Carlton). 2005;10(3):317-20.

4. Cholongitas E, Spyrou S, Georgousaki C, Dasenaki M. Comment on: Recurrent skin reaction attributable to darbepoetin alfa in a patient with chronic renal failure. Ren Fail. 2010;32(4):528

5. Garcia JE, Senent C, Pascual C, Fernandez G, Perez-Carral C, Diaz-Tejeiro $\mathrm{R}$, et al. Anaphylactic reaction to recombinant human erythropoietin. Nephron. 1993;65(4):636-7.

6. Weber G, Gross J, Kromminga A, Loew HH, Eckardt KU. Allergic skin and systemic reactions in a patient with pure red cell aplasia and anti-erythropoietin antibodies challenged with different epoetins. J Am Soc Nephrol. 2002;13(9):2381-3. 
7. Oh DJ. Anaphylaxis following the intravenous administration of continuous erythropoietin receptor activator in a haemodialysis patient. Nephrology (Carlton). 2014;19(5):304.

8. Bennett CL, Jacob S, Hymes J, Usvyat LA, Maddux FW. Anaphylaxis and hypotension after administration of peginesatide. N Engl J Med. 2014;370(21):2055-6.

9. Aziz N, Luna C, Mirza F, Tobin M. Anaphylactic Shock at the End of Hemodialysis. Semin Dial. 2015;28(6):661-4

10. Davila Fajardo CL, Pena Ortega M, Cabeza Barrera J, Prados Garrido MD. [Methoxy polyethylene glycol-epoetin beta (Mircera) in the treatment of a patient with chronic kidney disease presenting late-onset hypersensitivity to other epoetins]. Nefrologia. 2010;30(3):372-3. Spanish.

11. Tahan F, Akar HH, Dursun I, Yilmaz K. Desensitization of darbepoetin -alpha: a case report. Eur Ann Allergy Clin Immunol. 2013;45(5):176-7

12. Rosa JS, Vuong VB, Haskin O, Liu AY. A novel outpatient desensitization protocol for recombinant human erythropoietin allergy in a pediatric patient. Allergy Asthma Clin Immunol. 2018;14:8.

13. Wolf IH, Smolle J, Cerroni L, Kerl H. Erythroderma with lichenoid granulomatous features induced by erythropoietin. J Cutan Pathol. 2005; 32(5):371-4.

14. Jabr FI, Taher A. Recurrent skin reaction secondary to darbepoetin alfa for two months in a patient with chronic lymphocytic leukemia. Am J Hematol. 2007;82(3):245.
15. Norgard N, Wall GC. Possible drug rash with eosinophilia and systemic symptoms syndrome after exposure to epoetin alfa. Am J Health Syst Pharm. 2005;62(23):2524-6.

16. Ruano FJ, Garcimartin MI, Vazquez de la Torre M, Blanca M, Canto G. Desensitization of epoetin-alpha in a confirmed case of acute exanthematic pustulosis. Allergy. 2009;64(12):1797-8.

17. Schmutz JL, Barbaud A, Trechot P. [Epoetin alpha-induced acute generalized exanthematous pustulosis and desensitisation]. Ann Dermatol Venereol. 2010;137(11):761-2. French.

18. Cuxart M, Just M, Sans R, Matas M. [Generalized exfoliative dermatitis caused by erythropoietin]. Med Clin (Barc). 2000;115(4):158. Spanish.

19. Suh HY, Bae J, Kim HL, Kim KH, Cha RH, Ahn JY, et al. A Case of Acute Generalized Exanthematous Pustulosis after Injection of an Erythropoiesis-Stimulating Agent. Ann Dermatol. 2018;30(1):100-1.

20. Federalregister [Internet]. Washington DC: Office of the Federal Register; c2019 [cited 2019 Mar 25]. The Daily Journal of the United States Government; [about 2 screens]. Available from: https://www.federalregister .gov/documents/2019/02/13/2019-02146/takeda-pharmaceuticals-usa -inc-withdrawal-of-approval-of-a-new-drug-application-for-omontys 